\title{
ATENUASI DERAU ACAK DAN KOHEREN PADA DATA SEISMIK 2D DI PERAIRAN ARU, PAPUA
}

\section{ATTENUATION OF RANDOM AND COHERENT NOISE ON 2D SEISMIC DATA OF ARU WATERS, PAPUA}

\author{
Aldwin Adrianus ${ }^{1 *}$, Henry M. Manik ${ }^{2}$, \& Tumpal B. Nainggolan ${ }^{3}$ \\ ${ }^{1}$ Program Studi Ilmu dan Teknologi Kelautan, Fakultas Perikanan dan Ilmu Kelautan, \\ IPB University, Bogor, 16680, Indonesia \\ ${ }^{2}$ Departemen Ilmu dan Teknologi Kelautan, Fakultas Perikanan dan Ilmu Kelautan, \\ IPB University, Bogor, 16680, Indonesia \\ ${ }^{3}$ Pusat Penelitian dan Pengembangan Geologi Kelautan, Bandung, 40174, Indonesia \\ *E-mail: aldwinadrianus@gmail.com
}

\begin{abstract}
Seismic data always consists of the desired main signal and a noise component. Therefore, this study aims to reduce coherent and random noise in data by using different methods in order to increase the resolution of the data so that the interpretation of the data becomes accurate. Random noise can be removed easily by bandpass filtering and stacking with significant results while coherent noise has to go through more complex stages because coherent noise can overlap with data. Aru waters, where the data for this study was taken, is geographically located at the meeting point of 3 large active plates so that it has great potential in the oil and gas sector. This study uses two main methods to attenuate coherent noise to see the different results of the methods applied to data. The coherent filter which target swell noise and coherent denoising method which target linear coherent noise both produces satisfactory final results. These methods successfully attenuated main target noise that associated with both methods, but coherent denoising method still leaves a faint trace of swell noise inside cross section on the final result. The coherent filter method and the coherent denoising method are quite effective in identifying and attenuating random and coherent noise in the data, but the difference between the two methods lies in the noise target that can be attenuated maximally.
\end{abstract}

Keywords: coherent filter, random and coherent noise, spatial filter

\begin{abstract}
ABSTRAK
Data seismik selalu terdiri dari sinyal utama yang diinginkan dan komponen derau. Oleh karena itu penelitian ini bertujuan untuk meredam derau koheren dan acak pada data dengan menggunakan metode yang berbeda agar dapat meningkatkan resolusi data sehingga interpretasi data menjadi akurat. Derau acak dapat dihilangkan dengan mudah pada proses filter bandpass dan stacking dengan hasil yang signifikan, sedangkan derau koheren harus melalui tahapan yang lebih kompleks karena derau koheren dapat bertumpang tindih dengan data. Perairan Aru yang menjadi tempat data penelitian ini diambil, secara geografis berada pada lokasi bertemunya 3 lempeng benua yang aktif sehingga berpotensi dalam bidang migas. Penelitian ini menggunakan dua metode utama untuk mengatenuasi derau koheren untuk melihat bagaimana perbedaan penerapan kedua metode tersebut pada data. Metode koheren filter memiliki hasil akhir yang memuaskan, dengan target utama untuk menghilangkan swell noise dan berhasil dengan hasil yang signifikan. Metode koheren denoising disisi lain juga memiliki hasil akhir yang memuaskan, derau yang menjadi target adalah derau koheren linear yang bertumpang tindih dengan reflektor permukaan dan berhasil dengan hasil yang cukup signifikan, namun metode ini masih menimbulkan jejak samar dari swell noise pada penampang hasil akhir. Metode koheren filter dan metode denoising koheren cukup efektif dalam mengidentifikasi dan mengatenuasi derau acak maupun koheren pada data namun perbedaan kedua metode terletak pada target derau yang dapat diatenuasi dengan maksimal.
\end{abstract}

Kata kunci: derau acak dan koheren, filter koheren, filter spasial 


\section{PENDAHULUAN}

Data seismik selalu terdiri dari sinyal utama yang diinginkan dan komponen derau. Secara umum, segala jenis sinyal yang terekam selama proses akuisisi data dan mengganggu sinyal utama yang kita inginkan dapat dikategorikan sebagai derau. Terdapat dua jenis derau, yaitu derau koheren dan derau acak. Dalam akuisisi data seismik multichannel, derau acak cenderung lebih mudah diatenuasikan dan dihilangkan karena memiliki frekuensi yang beragam dan tidak menyerupai data primer seismik, sedangkan derau koheren tergolong sulit untuk diatenuasi secara sempurna pada saat proses pengolahan data dan cenderung berbaur dengan sinyal seismik asli dan oleh karena itu derau koheren seringkali diinterpretasikan sebagai sinyal dan menyebabkan kesalahan interpretasi yang fatal (Elboth \& Hermansen, 2009). Oleh karena itu, atenuasi derau merupakan tahapan yang penting dan krusial dalam pengolahan data seismik karena dapat berdampak signifikan terhadap hasil interpretasi akhir. Semua tahapan pengolahan data seismik memiliki tujuan utama untuk melemahkan derau dan menguatkan sinyal utama yang diinginkan (Nugraha et al., 2018). Penelitian ini menggunakan dua cara untuk mengatenuasi derau koheren yang umum digunakan yakni menerapkan filter koheren dan denoising koheren yang merupakan turunan dari algoritma TimeFrequency Denoising (TFDN). Menurut Elboth et al. (2008), hasil penelitiannya menunjukkan bahwa algoritma TFDN mendeteksi dan mengatenuasi derau pada domain frekuensi dan hasilnya sangat efektif untuk mengatenuasi derau yang memiliki frekuensi yang beragam, baik derau acak ataupun koheren. Tahap atenuasi derau merupakan tahapan yang penting dan krusial dalam pengolahan data seismik karena dapat berdampak signifikan terhadap hasil interpretasi akhir.

\section{METODE PENELITIAN}

\subsection{Waktu dan Lokasi Penelitian}

Penelitian dilakukan pada bulan Februari-Mei 2020 di Laboratorium Pemrosesan Sinyal Bawah Air, Departemen Ilmu dan Teknologi Kelautan, Fakultas Perikanan dan Ilmu Kelautan, IPB University dan Data Processing Laboratory, Pusat Penelitian dan Pengembangan Geologi Kelautan (PPPGL) Bandung. Akuisisi data dilakukan pada tahun 2014 oleh PPPGL menggunakan kapal riset Geomarin III yang dilengkapi dengan alat survei seismik di Laut Aru, Papua. Potensi gas biogenik, migas, dan energi laut di Laut Aru merupakan hal baru yang hendak diungkapkan dengan berbagai penelitian. Berdasarkan geografi, Kepulauan Aru termasuk kedalam Cekungan Wokam dan merupakan passive margin yang diduga mengandung potensi besar dalam bidang migas (Gumilar, 2017). Gambar 1 menampilkan peta lokasi dan lintasan akuisisi data.

\subsection{Metode Analisis Data \\ Menggunakan Filter Koheren dan Denoising Koheren}

Metode filter koheren pada dasarnya menerapkan pembobotan koherensi terhadap semua trace pada ensemble di domain frekuensi. Metode ini merupakan salah satu metode yang umum dan dasar untuk menghilangkan derau koheren serta acak. Namun seringkali metode ini digunakan untuk meredam swell noise dan seismic interference noise yang umum ditemukan pada data seismik. Pembobotan koherensi ini dilakukan pada semua frekuensi terkait yang diinput sebelumnya dengan menerapkan ambang batas yang umumnya merupakan frekuensi filter bandpass pada tahap editing. Pada proses ini dihitung rasio daya dari sinyal utama seismic dibandingkan dengan daya dari sinyal ditambah derau seismik pada setiap frekuensi yang sudah ditentukan ambang batas sebelumnya lalu diterapkan pada semua trace. Pembobotan koherensi 


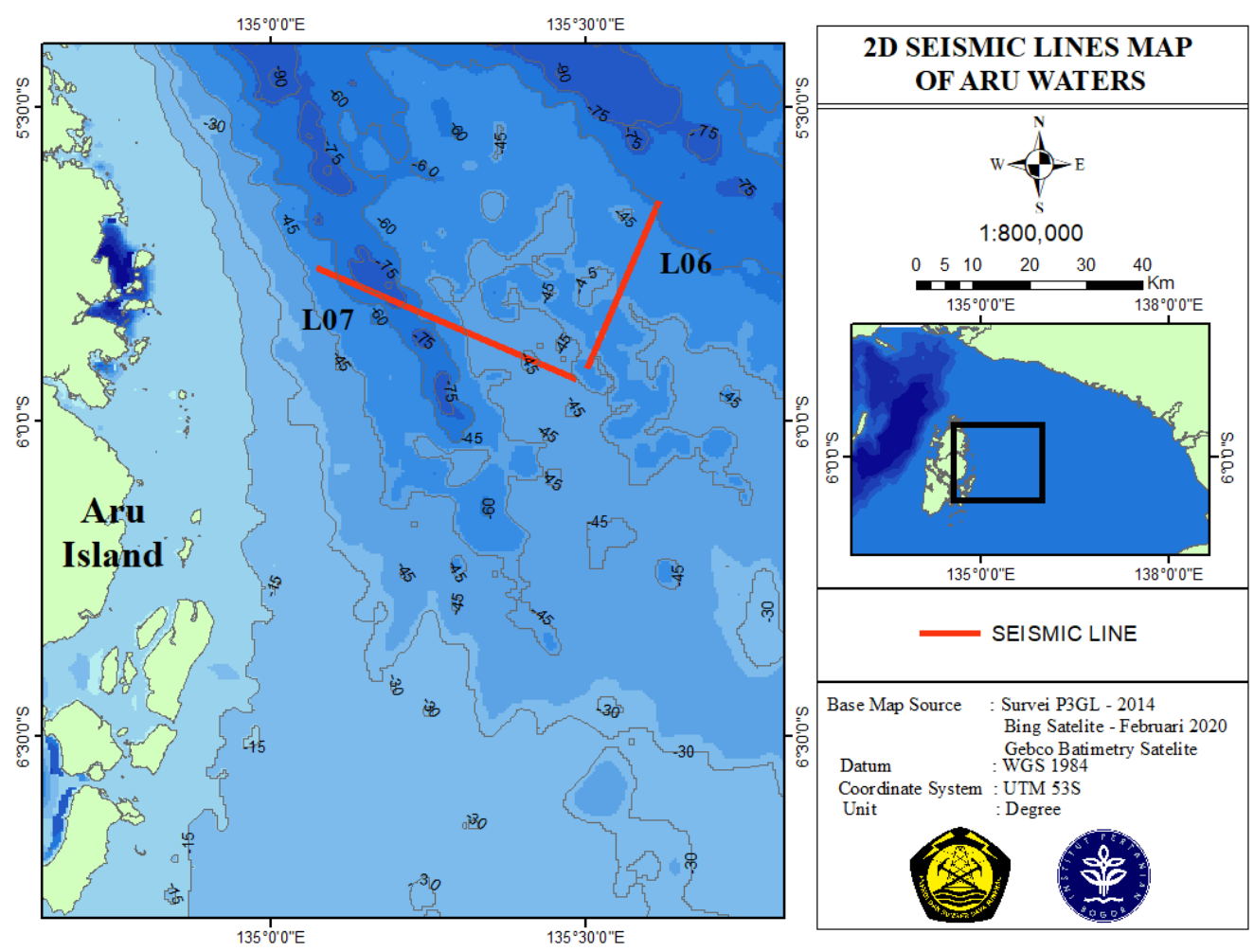

Gambar 1. Peta garis seismik.

Figure 1. Seismic line map.

dapat dinyatakan dengan persamaan matematis di bawah ini dengan $s$ sebagai daya sinyal seismik dan $n$ sebagai daya derau seismik:

$\frac{\sum s}{\sum s+n}$

Metode denoising koheren memiliki prinsip dasar cara kerja dengan menerapkan filter spasial terhadap data yang berada pada domain $\mathrm{f}-\mathrm{x}$ (frekuensi-jarak) untuk memprediksi dan kemudian meredam derau koheren dan utamanya adalah meredam derau linear koheren pada ensemble. Metode denoising koheren dapat digunakan untuk meredam berbagai macam derau koheren, namun lebih difokuskan kepada derau koheren linear. Perumusan secara matematis spasial filter berbasis Wiener Prediction Filter yang menggunakan operator filter prediktif $\left(a_{t}\right)$ dengan prediction distance $\alpha$, sehingga trace seismik yang dihasilkan $\left(Y_{T}\right)$ adalah estimasi input $\left(x_{t}\right)$ trace seismik pada waktu $t+\alpha$ dapat dinyatakan sebagai berikut (Peacock \& Treitel, 1969):

$Y_{T}=\sum_{t} x_{t} a_{T-t}=\hat{x}_{t+\alpha}$

\subsection{Pengolahan Data}

Pengolahan data penelitian ini terbagi menjadi 2 proses utama yakni preprocessing dan processing. Pengolahan data diawali dari input data dan diakhiri dengan Pre-Stack Time Migration (PSTM) yang kemudian digunakan pada analisis hasil. Diagram alir pengolahan data dapat dilihat pada Gambar 2.

Preprocessing merupakan tahap pertama dari pengolahan data seismik. Tahap ini sendiri terdiri dari 6 proses utama, yakni input data, geometry input, trace editting, true amplitude recovery, surface wave attenuation dan dekonvolusi. Tahap pertama adalah input data, data lapangan yang telah 


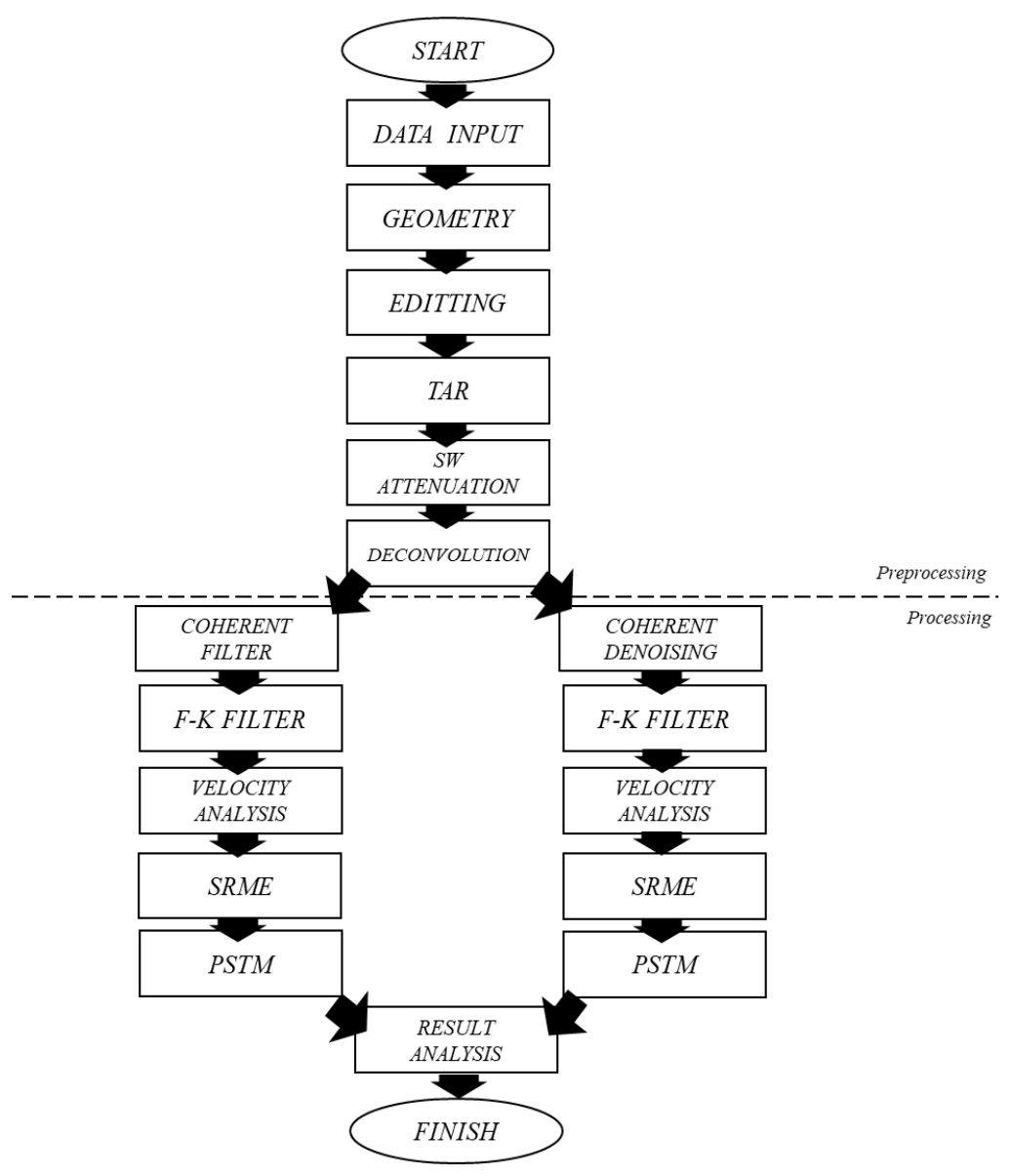

Gambar 2. Diagram alir pengolahan data seismik.

Figure 2. Flow chart of seismic data processing.

diakuisisi berbentuk pertembakan atau pershot kemudian digabungkan menjadi satu penampang. Data yang telah digabung disebut shot gather. Kemudian data tersebut yang kita gunakan untuk tahap selanjutnya. Tahap kedua adalah geometry input, setelah data digabungkan menjadi shot gather, kita perlu memasukkan parameter akuisisi. Parameter akuisisi tersebut adalah faktorfaktor yang digunakan untuk akuisisi data seperti jarak antara source dengan permukaan laut, jarak antara receiver dengan permukaan laut, jarak antara source, receiver dan lain-lain. Parameter akuisisi secara lengkap dapat dilihat pada Table 1.

Tahap ketiga adalah trace editing, pada tahap ini dilakukan trace-muting berupa top-mute dengan metode picking yang berguna untuk menghilangkan hasil perekaman data permukaan air. Kemudian menerapkan filter bandpass dengan frekuensi berbeda pada setiap lintasan untuk membuang frekuensi yang berada di atas ataupun di bawah frekuensi minimal karakteristik sinyal seismik yang berkisar antara 10-60 Hz (Kumar \& Ahmed, 2020). Tahap keempat adalah true amplitude recovery (TAR), tahap ini dilakukan untuk menampilkan kembali amplitudo seismik yang lemah ataupun hilang saat pengambilan data. Hilangnya amplitudo ini dapat disebabkan oleh macam-macam faktor saat gelombang merambat seperti geometrical spreading, variasi jarak sumber-penerima dan derau (Nainggolan et al., 2019). Tahap kelima adalah surface wave attenuation, tahap ini dilakukan untuk menghilangkan derau yang disebabkan oleh gelombang permukaan. Derau surface wave memiliki karakter amplitudo besar dengan frekuensi 
Tabel 1. Parameter akuisisi data seismik.

Table 1. Acquisition parameters of seismic data.

\begin{tabular}{lccc}
\hline \multicolumn{1}{c}{ Acquisition parameters } & unit & L06 & L07 \\
\hline Shot Point & - & 1303 & 1876 \\
Shot Interval & $\mathrm{m}$ & 25 & 25 \\
Group Interval & $\mathrm{m}$ & 12.5 & 12.5 \\
Active Channel & - & 60 & 60 \\
Interval Channel & $\mathrm{m}$ & 12.5 & 12.5 \\
Minimum Offset & $\mathrm{m}$ & 150 & 150 \\
Nominal Source Depth & $\mathrm{m}$ & 6 & 6 \\
Nominal Receiver Depth & $\mathrm{m}$ & 7 & 7 \\
\hline
\end{tabular}

kecil karena gelombang permukaan hanya menjalar di atas permukaan dasar perairan saja tanpa melakukan penetrasi ke dalam permukaan bumi. Tahap keenam yaitu dekonvolusi yang memiliki peran utama untuk meminimalisir short period multiple serta memampatkan wavelet seismik sehingga dapat meningkatkan resolusi temporal dari data seismik (Nainggolan et al., 2019). Metode dekonvolusi yang digunakan adalah dekonvolusi predictive, prinsip kerja metode ini adalah menganalisis bentuk permukaan dasar laut dan mencari bentuk wavelet yang menyerupai hasil picking di periode rendah, secara otomatis akan diduga sebagai multiple dari sinyal dasar perairan kemudian menghilangkannya (Chintia et al., 2017).

Selanjutnya masuk ke tahap processing, yang terdiri dari penerapan filter koheren atau metode denoising koheren, filter f-k, velocity analysis, Surface Related Multiple Elimination (SRME) dan migrasi. Setelah diterapkan filter koheren dan denoising koheren pada data, tahap selanjutnya adalah filter $\mathrm{f}-\mathrm{k}$. Tahap ini merupakan proses pemisahan sinyal dan derau pada domain $\mathrm{f}-\mathrm{k}$ (frekuensi-bilangan gelombang). Kemudian, tahap analisis kecepatan yang dilakukan pada penelitian ini menggunakan metode picking spectrum semblance. Metode ini dilakukan dengan memplot data CMP gather seismik terhadap waktu dan kecepatan kemudian melakukan picking nilai kecepatan secara vertikal pada semblance CMP gather. Beberapa hal yang harus diperhatikan dalam analisis kecepatan ini adalah grafik kecepatan interval harus membentuk grafik yang positif (ke arah kanan) dan picking fungsi kecepatan yang baik dilakukan pada spectrum nilai frekuensi yang tinggi. Selanjutnya, tahap SRME yang merupakan metode multiple elimination dan difokuskan untuk menghilangkan multiple yang berhubungan dengan permukaan (Safitri et al., 2020). Pada metode ini dilakukan picking water bottom pada data seismik pre-stack yang kemudian data hasil picking tersebut digunakan untuk memprediksi model surface related multiple dan kemudian menghilangkannya. Setelah itu masuk ke tahap terakhir processing data yakni migrasi. Tahap PSTM adalah metode untuk mengembalikan posisi reflektor ke posisi sejatinya untuk meningkatkan resolusi temporal data secara signifikan (Sidiq et al., 2019).

\section{HASIL DAN PEMBAHASAN}

Derau acak merupakan derau yang tergolong mudah untuk diatenuasikan karena tidak memiliki korelasi, baik temporal ataupun spasial dengan data primer seismik. Menurut Dondurur \& Karsli (2012), derau acak mudah untuk diidentifikasi karena memiliki amplitudo yang tinggi, frekuensi yang rendah dan mayoritas mengambil bentuk garis vertikal di sepanjang tampilan trace seismik, sehingga bentuknya sangat 
berbeda dengan reflektor primer seismik. Contoh derau acak ini adalah direct arrival yang diakibatkan oleh gelombang sumber saat memancarkan langsung terekam oleh receiver tanpa penetrasi ke lapisan bumi, tugging noise dan strumming noise yang diakibatkan oleh pergerakan secara tiba-tiba receiver saat proses perekaman data oleh karena ombak dan cavitation noise yang diakibatkan oleh pergerakan fluida karena baling-baling kapal di sekitar receiver saat perekaman data. Derau acak dapat diatenuasi menggunakan berbagai metode seperti filter low cut, filter bandpass, trace muting, dan filter f-k yang mayoritas dilakukan pada tahapan preprocessing. Penelitian ini menerapkan trace muting dan filter bandpass pada tahap preprocessing yang meredam mayoritas dari derau acak, kemudian diterapkan pula filter $\mathrm{f}-\mathrm{k}$ pada tahap processing lanjutan untuk menghilangkan dan meredam derau acak sepenuhnya.

Derau koheren berkebalikan dengan derau acak, derau koheren mayoritas memiliki korelasi baik spasial maupun temporal dengan data primer seismik (Elboth et al., 2010). Derau koheren tergolong sulit untuk diindentifikasi karena sebagian besar memiliki bentuk yang serupa dengan tampilan reflektor primer dan dapat mengakibatkan kesalahan interpretasi swell noise dan seismic interference merupakan contoh dari derau koheren. Ada berbagai macam metode untuk menghilangkan pengaruh derau koheren pada data, penelitian ini menggunakan dua metode untuk menghilangkan pengaruh derau koheren pada data. Metode yang digunakan adalah dengan menerapkan filter koheren dan denoising koheren.

Metode koheren filter memilki hasil yang cukup signifikan dalam menghilangkan swell noise yang memiliki amplitudo menyerupai data primer seismik dengan frekuensi yang beragam. Hasil yang didapat setelah menerapkan metode ini dapat dilihat pada Gambar 4 dan 5. Gambar 4 merupakan gambar shot gather dari lintasan L07 dengan nomor FFID 1227. Dapat dilihat pada Gambar 4, kotak kuning mengindikasikan swell noise yang berada pada data yang sudah teratenuasi sedangkan lingkaran merah adalah seismic interference noise yang teratenuasi. Menurut Elboth et al. (2010), swell noise adalah derau dengan amplitudo tinggi dan dapat memengaruhi trace disekitarnya, umumnya berada pada frekuensi dibawah $15 \mathrm{~Hz}(<15 \mathrm{~Hz})$. Pada tampilan trace berbentuk seperti gelembung vertikal dan disebabkan oleh guncangan terhadap receiver (hydrophone) saat perekaman. Guncangan tersebut bisa berasal
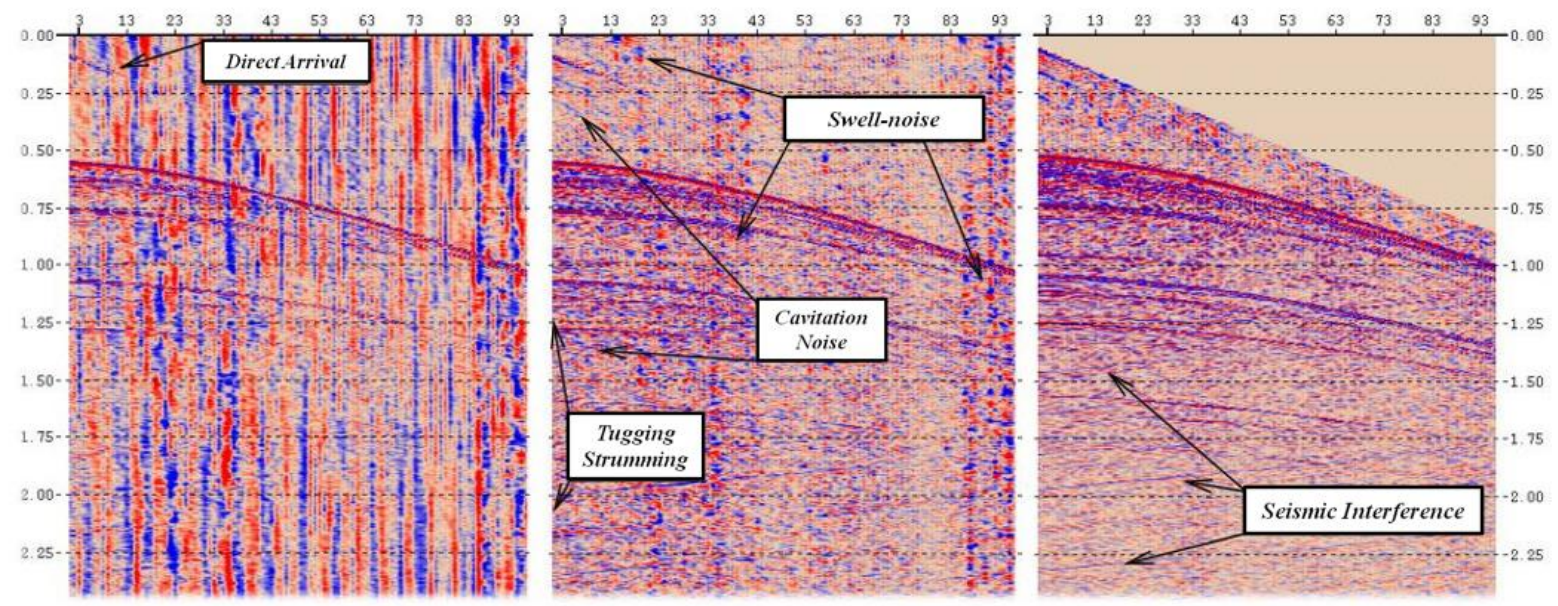

Gambar 3. Contoh derau acak dan koheren (Elboth et al., 2010).

Figure 3. Examples of random and coherent noise (Elboth et al., 2010). 



Gambar 4. Tampilan data pengambilan gambar garis L07 sebelum (kiri) dan sesudah (kanan) penerapan filter koheren.

Figure 4. Shot gather data display of line L07 before (left) and after (right) the application of coherent filter.

dari cuaca atau aktifitas di sekitar receiver sehingga membuat gelombang dan arus yang mengganggu hydrophone. Seismic interference noise adalah derau yang disebabkan oleh perekaman gelombang seismik yang berasal dari sumber lain seperti airgun dari kapal seismik lain ataupun gelombang seismik dari mamalia laut. Derau ini memiliki frekuensi yang beragam dan cenderung memiliki amplitudo data yang lebih tinggi daripada data primer seismik.

Gambar 5 merupakan gambar shot gather dari lintasan L06 dengan nomor FFID 1032. Lintasan L06 memiliki konsentrasi derau acak dan koheren yang relatif sama dibandingkan dengan lintasan L07, namun pada lintasan L06 tidak ditemukan seismic interference noise seperti pada lintasan L07. Perbedaan kemunculan derau ini dapat diakibatkan oleh berbagai macam faktor saat perekaman data seperti kondisi cuaca dan aktifitas di sekitar receiver saat perekaman data. Kotak kuning pada Gambar 5 menunjukkan swell noise yang teratenuasi dengan baik. Hal ini sesuai dengan penelitian
Elboth et al. (2008) yang menunjukkan bahwa metode ini sangat efektif untuk menghilangkan derau terutama swell noise pada data karena menggunakan dasar algoritma dari time frequency de-noising (TFDN) yang dapat mengatenuasi derau dengan frekuensi yang beragam.

Metode denoising koheren dapat juga digunakan untuk mengatenuasi berbagai macam derau koheren, namun lebih difokuskan kepada derau koheren linear. Menurut Yilmaz (2001) derau koheren linear terbagi menjadi dua jenis utama yakni guided waves noise dan side scattered energy noise. Guided waves noise disebabkan oleh sedimen permukaan bumi di bawah laut yang halus seperti lumpur sehingga menyebabkan gelombang seismik menjalar secara horizontal dan tidak melakukan penetrasi lebih dalam daripada lapisan ini. Semakin dangkal kedalaman muka air tempat melakukan akuisisi data dan semakin halus sedimen lapisan permukaan bumi akan meningkatkan secara signifikan pengaruh dari derau ini. Derau ini cenderung berada 

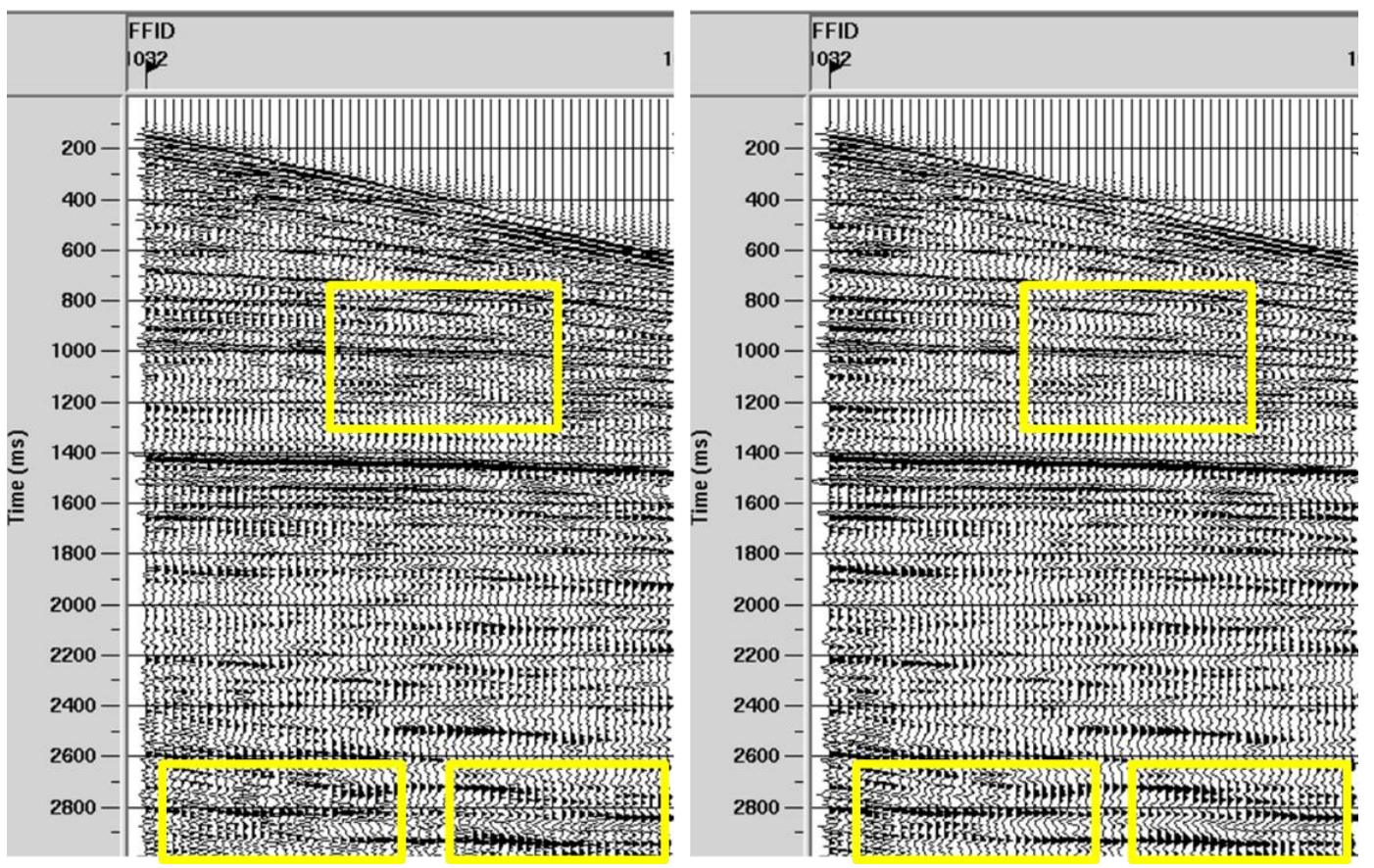

Gambar 5. Bidikan mengumpulkan data tampilan garis L06 sebelum (kiri) dan sesudah (kanan) penerapan filter koheren.

Figure 5. Shot gather data display of line L06 before (left) and after (right) the application of coherent filter.

pada low velocity trace seismik dengan frekuensi dan amplitudo beragam yang dekat dengan permukaan dan dapat menumpangtindih refleksi utama dari gelombang seismik di trace dekat dengan reflektor pertama. Sedangkan side scattered energy noise memiliki karakteristik frekuensi dan amplitudo yang menyerupai refleksi primer dari gelombang seismic, namun memiliki moveout range yang jauh lebih tinggi daripada refleksi primer dari gelombang seismik. Oleh karena itu, penampakan derau ini pada penampang trace seismik terlihat lebih melengkung daripadagelombang primer dan berada di zona dalam yang merupakan zona trace dengan karakteristik kecepatan tinggi (high velocity) dan menumpang-tindih gelombang primer pada zona tersebut (Yilmaz, 2001).

Hasil yang didapat setelah menerapkan metode ini dapat dilihat pada Gambar 6 dan 7. Gambar 6 merupakan gambar shot gather dari lintasan L07 dengan nomor FFID 2752. Dapat dilihat pada
Gambar 6, kotak hijau merupakan hasil atenuasi dari guided waves noise yang berada pada low velocity trace di dekat reflektor permukaan dari seismik. Hasil yang didapat dilihat cukup signifikan dalam mengatenuasi derau sehingga reflektor pertama terlihat lebih bersih dan tidak ditemukan adanya indikasi side scattered energy noise sehingga secara keseluruhan hasil memiliki resolusi yang lebih tinggi. Lingkaran merah merupakan swell noise yang juga teratenuasi namun metode ini tidak terlalu signifikan dalam mengatenuasi swell noise karena masih terdapat jejak swell noise yang samar terlihat. Gambar 7 merupakan gambar shot gather dari lintasan L06 dengan nomor FFID 1032. Gambar 7 memiliki konsentrasi derau acak dan koheren yang relatif sama dibandingkan dengan lintasan L06. Terlihat pada Gambar 7 memiliki hasil yang hampir menyerupai Gambar 6, kotak hijau merupakan hasil atenuasi dari guided waves noise yang cukup signifikan perbedaannya dan juga tidak ditemukan jejak side scattered 


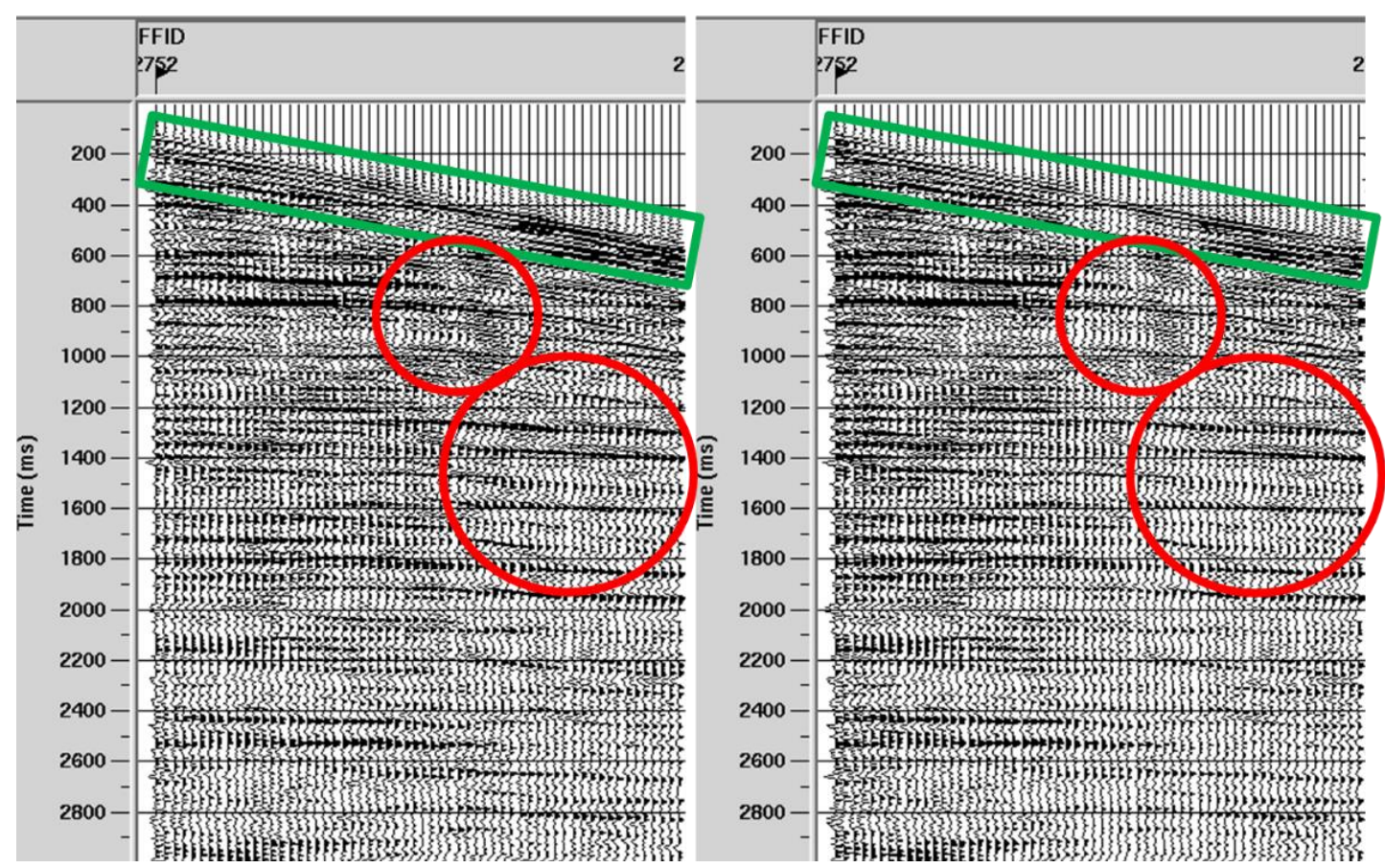

Gambar 6. Tampilan data shot mengumpulkan garis L07 sebelum (kiri) dan sesudah (kanan) penerapan denoising yang koheren.

Figure 6. Shot gather data display of line L07 before (left) and after (right) the application of coherent denoising.
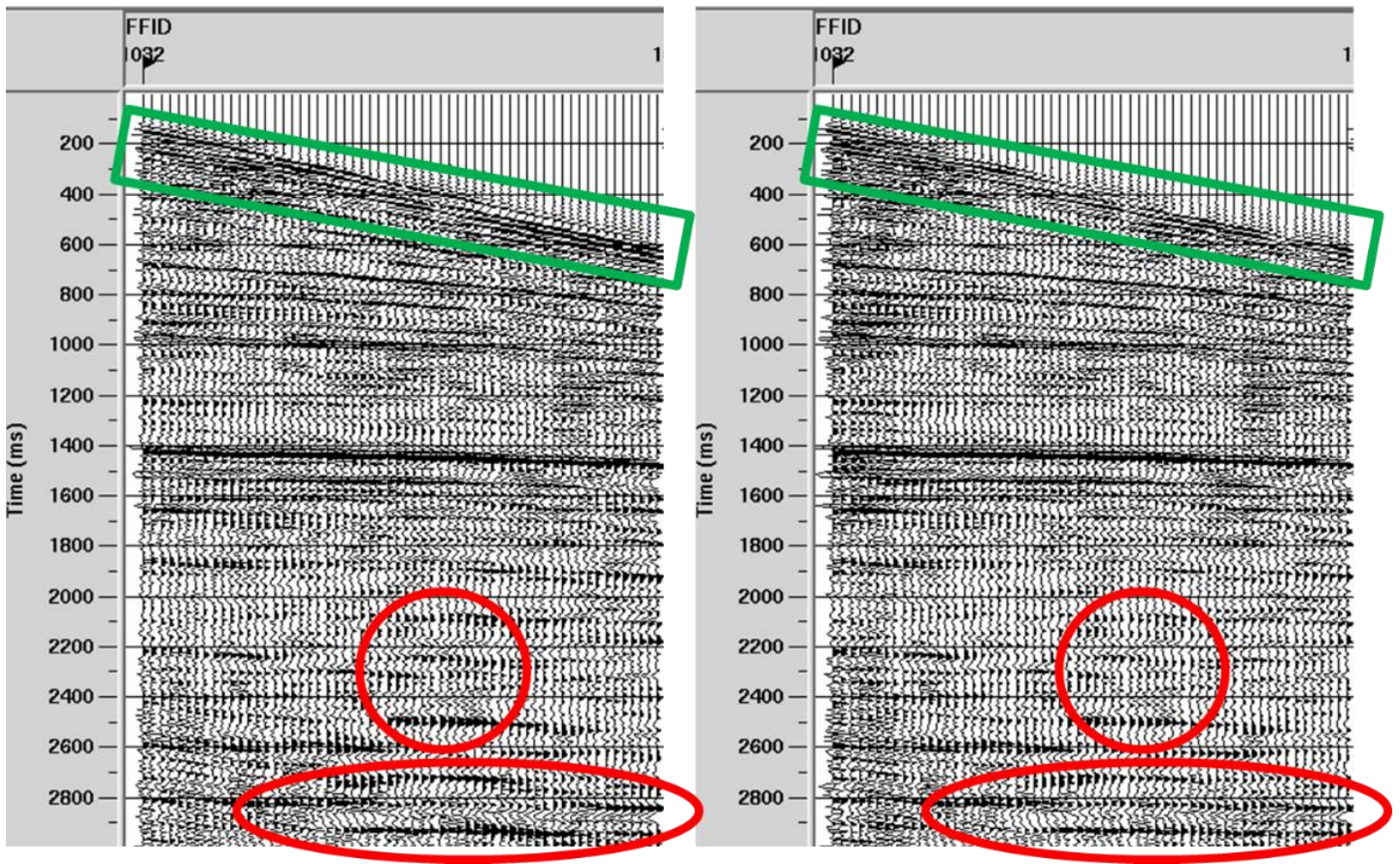

Gambar 7. Tampilan data shot mengumpulkan garis L06 sebelum (kiri) dan sesudah (kanan) penerapan denoising yang koheren.

Figure 7. Shot gather data display of line L06 before (left) and after (right) the application of coherent denoising. 
energy noise sehingga secara keseluruhan menghasilkan trace yang lebih bersih dan memiliki resolusi yang lebih tinggi. Lingkaran merah menunjukkan swell noise yang teratenuasi juga, namun sama seperti Gambar 6 swell noise yang teratenuasi tidak terlalu signifikan karena masih ditemukan jejak derau yang samar terlihat. Hal ini sesuai dengan penelitian Guo \& Lin (2003) yang menggunakan metode denoising koheren berbasis filter spasial untuk memprediksi dan mengatenuasi derau koheren linear berfrekuensi tinggi dan berhasil mengatenuasi derau target secara signifikan. Menurut Yilmaz (2015) metode ini memang kurang efektif untuk menghilangkan seismic interference noise karena metode ini menerapkan filter spasial pada domain frekuensi yang didesain untuk mengidentifikasi dan mengatenuasi derau koheren linear sehingga kurang baik untuk mendeteksi seismic interference noise yang tergolong derau koheren nonlinear.

Hasil akhir dari penampang seismik didapatkan setelah melakukan tahapan migrasi. Metode migrasi yang digunakan adalah pre-stack kirchoff time migration. Metode ini dilakukan berdasarkan domain waktu. Tujuan utama dalam proses migrasi adalah meningkatkan resolusi dari penampang seismik dengan cara mengatenuasikan efek difraksi gelombang (gelombang semu) yang terbentuk karena struktur permukaan bumi yang kompleks seperti adanya patahan, dan juga mengembalikan posisi reflektor ke posisi sejatinya (Sidiq et al., 2019). Efek dari penerapan metode atenuasi derau koheren baik filter koheren maupun denoising koheren memang sejatinya tidak terlalu terlihat dengan jelas, menurut Yilmaz (2001) hal ini disebabkan oleh sebagian besar derau koheren maupun acak memang cenderung tidak muncul pada data gabungan dari common depth point (CDP). Namun jejakjejak derau koheren yang teratenuasi pada hasil penampang migrasi dengan masing masing metode masih dapat dibandingkan dan dapat diidentifikasi.

Hasil perbandingan penerapan kedua metode atenuasi derau koheren dapat dilihat pada Gambar 8 dan Gambar 9. Gambar 8 merupakan gambar hasil penampang seismik lintasan L07, dan Gambar 9 merupakan gambar hasil penampang seismik lintasan L06 dengan Gambar 9a merupakan perlakuan dari metode filter koheren dan Gambar 9b merupakan perlakuan dari metode denoising koheren. Kotak hitam memperlihatkan perbedaan ketajaman reflektor permukaan yang mana pada bagian Gambar 8a dan Gambar 9a reflektor permukaan masih tersisipi oleh guided waves noise (derau koheren linear) sehingga membuat resolusi pada penampang permukaan lebih rendah jika dibandingkan dengan bagian Gambar 8b

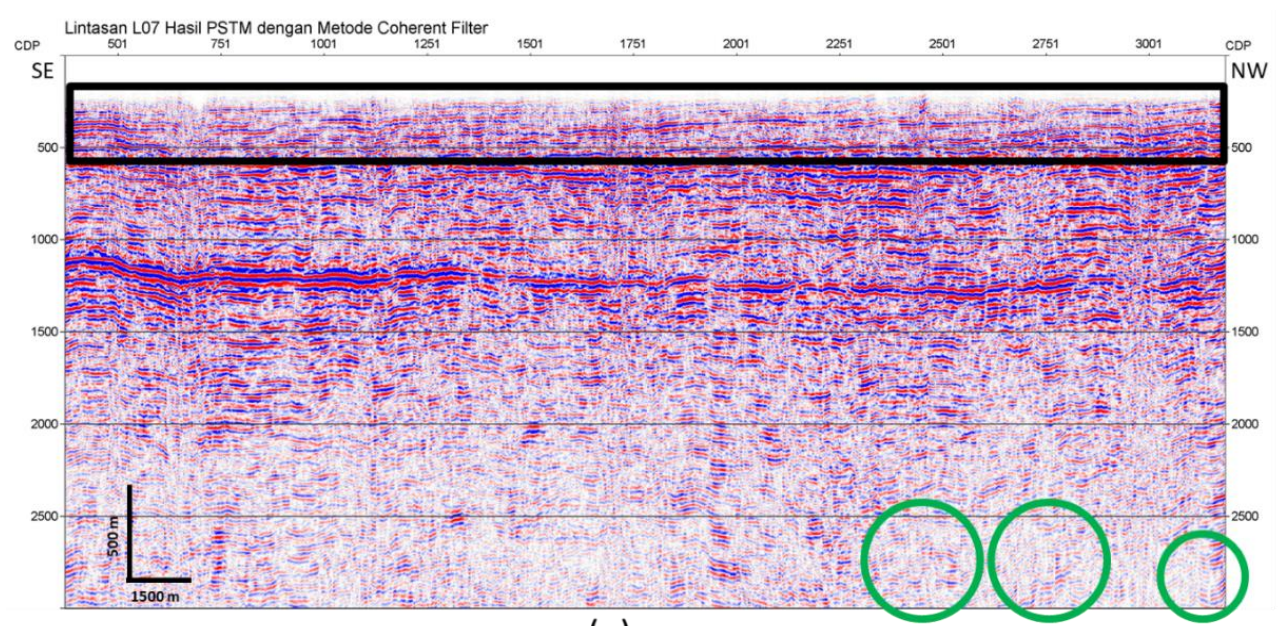

(a) 


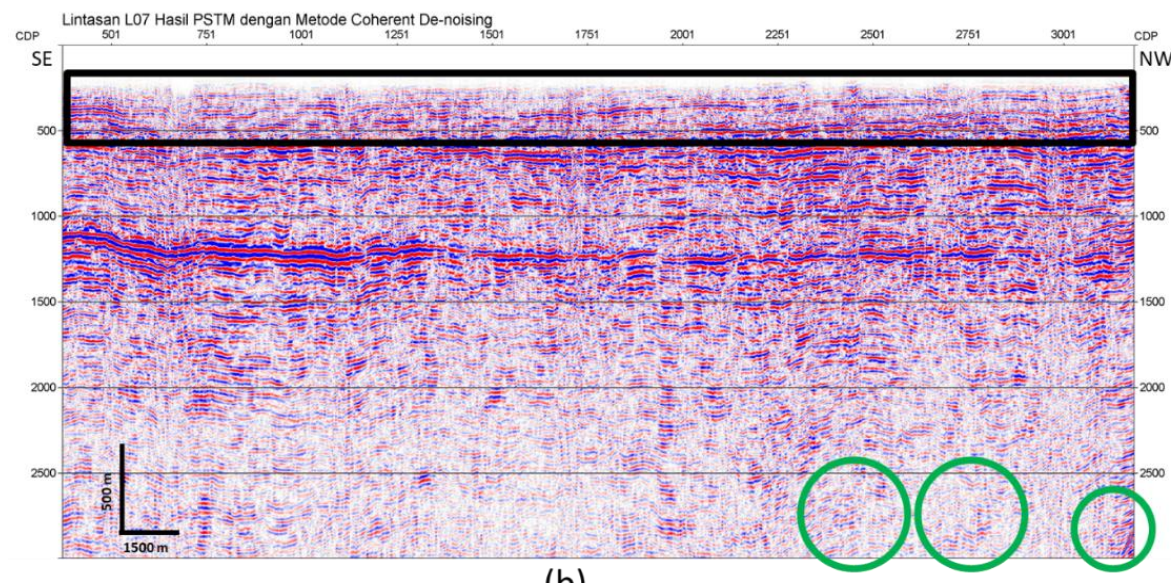

(b)

Gambar 8. Tampilan hasil akhir penampang seismik garis L07 dengan menerapkan metode (a) filter koheren dan (b) denoising koheren.

Figure 8. Display of the final result of the seismic cross section of line L07 by applying the methods (a) coherent filter and (b) coherent denoising.
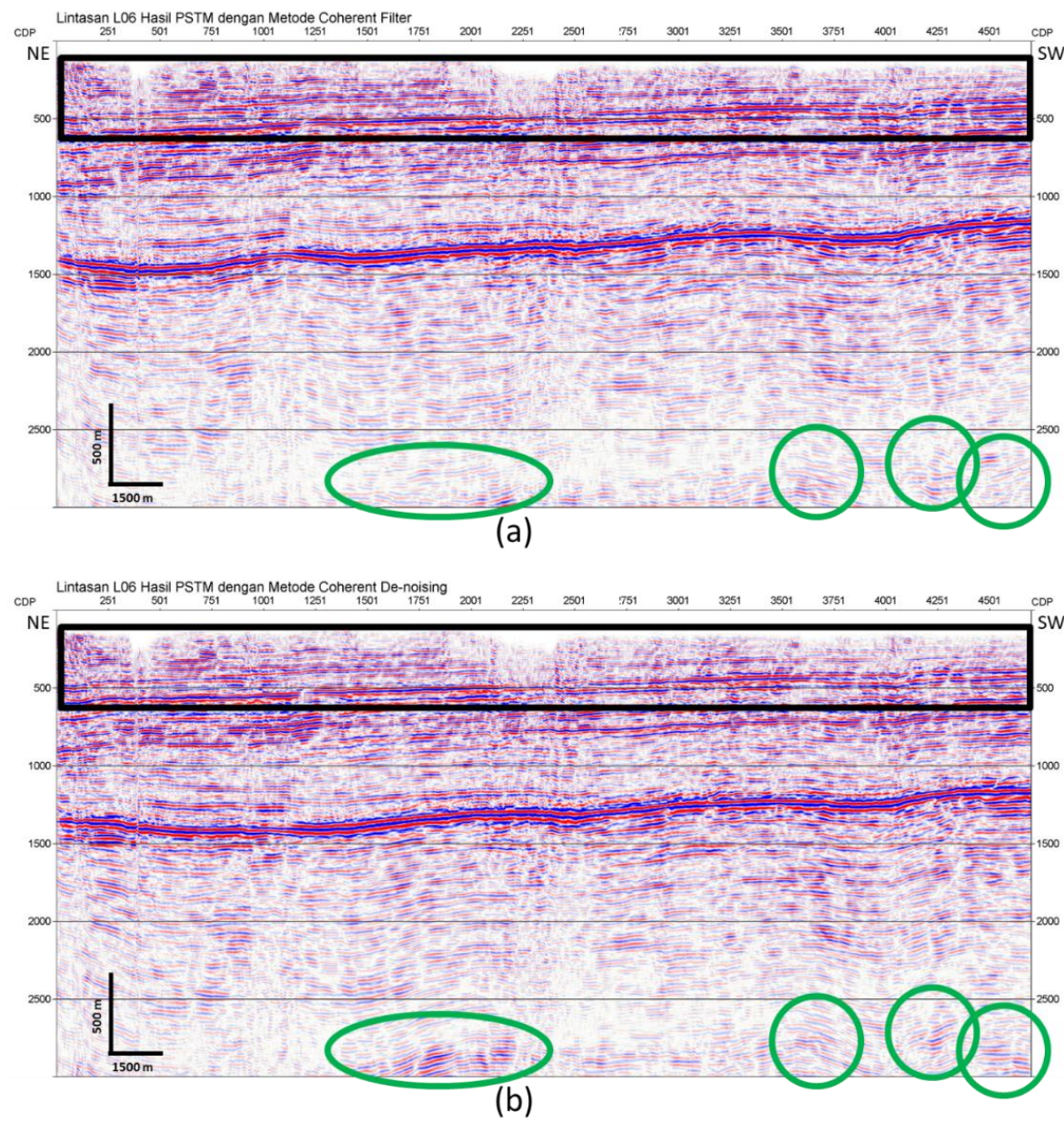

Gambar 9. Tampilan hasil akhir penampang seismik garis L06 dengan menerapkan metode (a) filter koheren dan (b) denoising koheren.

Figure 9. Display of the final result of the seismic cross section of line LO6 by applying the methods (a) coherent filter and (b) coherent denoising 
dan Gambar 9b. Namun bagian Gambar 8a dan Gambar 9a memiliki jejak-jejak swell noise yang sudah teratenuasi dengan baik seperti yang ditunjukkan oleh lingkaran hijau jika dibandingkan dengan Gambar $8 \mathrm{~b}$ dan Gambar 9b.

\section{KESIMPULAN}

Metode filter koheren dan metode denoising koheren cukup efektif dalam mengidentifikasi dan menghilangkan derau acak maupun koheren pada data, hal ini dapat dilihat pada hasil akhir penampang seismik yang tidak terlalu berbeda secara signifikan namun derau target mayoritas sudah teratenuasi. Perbedaan kedua metode terletak pada target derau yang dapat diatenuasi dengan maksimal, metode filter koheren sangat efektif untuk mengidentifikasi dan menghilangkan derau acak serta swell noise pada data sedangkan metode denoising koheren sangat efektif untuk menghilangkan derau koheren linear yang cenderung bertumpang tindih pada sinyal primer. Penggunaan kedua metode atenuasi derau ini akan sangat baik jika diterapkan secara bersamaan pada data untuk mendapatkan hasil yang maksimal.

\section{UCAPAN TERIMA KASIH}

Penulis mengucapkan terima kasih kepada Pusat Penelitian dan Pengembangan Geologi Kelautan (PPPGL) Bandung atas izin penggunaan data dan fasilitas selama proses pengerjaan hingga penelitian ini dapat terselesaikan. Ucapan terima kasih juga penulis sampaikan kepada Prof. Henry Munandar Manik, Ph.D. dan Tumpal Bernhard Nainggolan, S.T, M.T. atas bantuannya dalam menyiapkan artikel penelitian ilmiah ini.

\section{DAFTAR PUSTAKA}

Chintia, B., O. Ivansyah, \& J. Sampurno. 2017. Analisis parameter gap dalam tahapan dekonvolusi prediktif guna mereduksi short period multiple dan meningkatkan $\mathrm{S} / \mathrm{N}$ ratio pada pengolahan data seismik refleksi $2 \mathrm{D}$ marine. J. Positron, 7(1): 25-33.

https://doi.org/10.26418/positron.v7i1 .20783

Dondurur, D. \& H. Karsli. 2012. Swell noise suppression by wiener prediction filter. J. of Applied Geophysics, 80: 91-100.

https://doi.org/10.1016/j.jappgeo.201 2.02 .001

Elboth, T. \& D. Hermansen. 2009. Attenuation of noise in marine seismic data. In: SEG Technical Program Expanded Abstracts. Society of Exploration Geophysicists. 3312$3316 \mathrm{pp}$. https://doi.org/10.1190/1.3255547

Elboth, T., I.V. Presterud, \& D. Hermansen. 2010. Time-frequency seismic data de-noising. J. Geophysical Prospecting, 58(3): 441-453. https://doi.org/10.1111/j.13652478.2009.00846.x

Elboth, T., H.H. Qaisrani, \& Hertweck, T. 2008. De-noising seismic data in the time-frequency domain. In: SEG Technical Program Expanded Abstracts. Society of Exploration Geophysicists. 2622-2626 pp. https://doi.org/10.1190/I.3063887

Gumilar, S.I. 2017. Periode deformasi kenozoikum Kepulauan Aru, Cekungan Wokam, Maluku. $J$. Geologi dan Sumberdaya Mineral, 18(2): 89-103. https://doi.org/10.33332/jgsm.geologi .v18i2.186

Guo, J. \& Lin D. 2003. High-amplitude noise attenuation. In: SEG Technical Program Expanded Abstracts. Society of Exploration Geophysicists. 1893$1896 \mathrm{pp}$.

https://doi.org/10.1190/I.1817688

Kumar, D. \& I. Ahmed. 2020. Seismic noise. In: Gupta H.K. (ed.). Encyclopedia of 
solid earth geophysics, Encyclopedia of earth sciences series. Springer Nature. Switzerland. 1-6 pp. https://doi.org/10.1007/978-90-4818702-7_146-1

Nainggolan, T.B., S.M. Rasidin, \& I. Setiadi. 2019. Combined multiple attenuation methods and geological interpretation: seram sea case study 2D marine seismic data. Bulletin of the Marine Geology, 34(1): 17-28. https://doi.org/10.32693/bomg.34.1.2 019.622

Nugraha, D.M., A.S. Bahri, \& D.D. Warnana. 2018. Aplikasi transformasi curvelet untuk denoising random noise: studi kasus data seismik sintetik 2D darat "antiklin". J. Teknik ITS, 7(1): 46-69. https://doi.org/10.12962/j23373539.v $7 \mathrm{i} 1.27883$

Peacock, K.L. \& Treitel, S. 1969. Predictive deconvolution: theory and practice. $J$. Geophysics, 34(2): 155-169. https://doi.org/10.1190/1.1440003

Safitri, D., T.B. Nainggolan, \& H.M. Manik. 2020. Common reflection surface methods in low fold coverage. IOP Conference Series: Earth and Environmental Science, 429: 1-10. https://doi.org/10.1088/1755-

1315/429/1/012032

Sidiq, A.P., H.M. Manik, \& T.B. Nainggolan. 2019. Studi komparasi metode migrasi seismik dalam mengkarakterisasi reservoir migas di Blok Kangean, Laut Bali menggunakan inversi impedansi akustik berbasis model. J. Ilmu dan Teknologi Kelautan Tropis, 11(1): 205-219.

https://doi.org/10.29244/jitkt.v11i1.23 028

Yilmaz, Ö. 2001. Noise and multiple attenuation. in: Seismic data analysis. Chapter 6. Society of Exploration Geophysicists, 837-1000 pp. https://doi.org/10.1190/1.9781560801 580

Yilmaz, Ö. 2015. Engineering seismology: with application to geotechnical engineering. Society of Exploration Geophysicists, 964 p. https://doi.org/10.1190/1.9781560803 300

Received : 07 December 2020

Reviewed : 21 January 2021

Accepted : 07 March 2021 
